\title{
Intraocular pressure (IOP) after intravitreal dexamethasone implant (Ozurdex) amongst different geographic populations- GEODEX-IOP study
}

\author{
Ashish Sharma ${ }^{1}$ Baruch D Kuppermann ${ }^{2}$. Francesco Bandello ${ }^{3}$ Paolo Lanzetta ${ }^{4}$ Dinah Zur DiD $^{5}$. \\ Sung Wook Park ${ }^{6,7} \cdot$ Hyeong Gon Yu ${ }^{6}{ }^{6} \cdot$ V. R. Saravanan ${ }^{8} \cdot$ Leandro Cabral Zacharias $^{9} \cdot$ Alan K Barreira $^{9} \cdot$ \\ Matias Iglicki ${ }^{10} \cdot$ Fernando Miassi $^{11} \cdot$ Daniele Veritti $^{4} \cdot$ Sean Tsao ${ }^{2} \cdot$ Deepika Makam $^{1} \cdot$ Nidhee Jain $^{8}$. \\ Anat Loewenstein ${ }^{5}$
}

Received: 5 March 2019 / Revised: 29 June 2019 / Accepted: 31 July 2019 / Published online: 30 September 2019

(c) The Author(s), under exclusive licence to The Royal College of Ophthalmologists 2019

\begin{abstract}
Purpose To analyse the intraocular pressure rise after intravitreal dexamethasone implant (Ozurdex) amongst different geographic populations.

Methods The medical charts of 294 dexamethasone implants between February 2011 and 2017 were reviewed retrospectively. South Asian (India), White (Europe, US and Israel) Latino (Argentina and Brazil) patient data was included in the study. Ocular hypertension (OHT) was defined as intraocular pressure of $>25 \mathrm{mmHg}$ or an increase of at least $10 \mathrm{mmHg}$ from baseline. The main indications for treatment were diabetic macular edema (ME) (65.6\%), retinal vein occlusion (26.5\%), uveitis (7.8\%).

Results Amongst 294 intravitreal implants, ocular hypertension ( $>25 \mathrm{mmHg}$ ) was recorded in 0,8 and $9.5 \%$ in White, Latino, and South Asian groups, respectively. However, IOP $>20 \mathrm{mmHg}$ was recorded in $14 \%$, 28\% and $27 \%$ in White, Latino, and South Asian groups, respectively. Incidence of very high IOP (>35 mmHg) was lower in all geographical groups. It was $3 \%$ in Latino followed by $2 \%$ in South Asian group.

Conclusion Latino and South Asian groups have higher IOP rise compared to White population. Most patients with elevated IOP fluctuate between $20-25 \mathrm{mmHg}$.
\end{abstract}

Intraocular pressure (IOP) rise after Dexamethasone implant differs in different Geographic groups. South Asian and Latino groups have significantly higher incidence of IOP rise compared to Whites.

Ashish Sharma

drashish79@hotmail.com

1 Lotus Eye Hospital and Institute, Avinashi Road, Coimbatore, TN, India

2 Gavin Herbert Eye Institute at the University of California, Irvine, CA, USA

3 University Vita-Salute, Scientific Institute San Raffaele, Milano, Italy

4 Department of Ophthalmology, University of Udine, Udine, Italy

5 Division of Ophthalmology, Tel Aviv Sourasky Medical Center And Sackler Faculty of Medicine, Tel Aviv University, Tel Aviv, Israel

\section{Introduction}

Intraocular steroid therapy has always been considered as second line due to their unfavourable side effect profile in terms of rise in intraocular pressure (IOP) and cataract formation. In steroid-induced glaucoma, the IOP is elevated primarily due to increased outflow resistance. Increased

6 Department of Ophthalmology, Seoul National University Hospital, Seoul 03080, Republic of Korea

7 Seran Eye Center, Seoul 06167, Republic of Korea

8 Department of Vitreoretina, Aravind Eye Hospital, Coimbatore, TN, India

9 University of Sao Paulo Medical School Allan Kardec Barreira: Attending- University of Sao Paulo; Medical Director- HCLOE Eye Hospital, Sao Paulo, Brazil

10 Private Retina Service. University of Buenos Aires, Buenos Aires, Argentina

11 Rosario Retina Clinic, Rosario, Argentina 
responsiveness to steroids may be facilitated by upregulation of glucocorticoid receptors on trabecular meshwork cells [1]. In cultured human trabecular meshwork cells, glucocorticoids increase the expression of the extracellular matrix protein fibronectin, glycosaminoglycans, and elastin [2, 3]. Steroids also suppress phagocytic activity which may lead to observations such as increased deposition of material in the juxtacanalicular meshwork of eyes with steroid-induced glaucoma $[4,5]$. Actual physical obstruction by the steroid medication has been postulated as well, based on the observation of White crystals in the angle of a patient who developed elevated IOP after intravitreal triamcinolone injection [6]. Furthermore, triamcinolone has also been shown to be toxic on human trabecular meshwork cells in vitro [7]. Introduction of dexamethasone implant (Ozurdex) has given another steroid option for the treatment of macular oedema (ME) secondary to retinal vein occlusion RVO [8], diabetes (DME) [9], postsurgical [10], and uveitis [11]. Similar to other ocular steroids, studies have evaluated the incidence of cataract and IOP rise after Ozurdex therapy. Most of the studies have demonstrated that IOP rise after Ozurdex is less than other steroids such as triamcinolone acetonide or fluocinolone acetonide. Episodes of ocular hypertension (OHT) are usually transient and successfully controlled with topical treatment [12].

Numerous studies have investigated the IOP as a part of safety of the Ozurdex including the trials done for clinical approval of Ozurdex [8-11]. However, none of the study tried to find out if it varies with geographic region. Most of the previous studies were limited to one region [13, 15-21].

Glaucoma incidence and prevalence varies in different geographic regions as evident by multiple studies [22]. To the best of our knowledge, this is the first study that analyses real life IOP following steroidal implant in multiple geographic regions. The objective of this study is to report the incidence of OHT in real world amongst different geographic populations following Ozurdex Implant.

\section{Materials and methods}

A descriptive, observational, retrospective, consecutive, uncontrolled multi geographic study of 294 implants was conducted including South Asian (India), Whites (Europe and USA), and Latino (Argentina, Brazil) population. Institutional Review Board approval was obtained at each participating centre. In addition, the study adhered to the tenets of the Declaration of Helsinki. Informed consent was obtained from all the patients.

All consecutive patients with at least one intravitreal injection of dexamethasone implant $0.7 \mathrm{mg}$ (Ozurdex) from February 2011 to February 2017 were included in this study. IOP was measured with Goldmann applanation tonometer at baseline or confirmation if it's found $>20 \mathrm{mmHg}$ with any other method. IOP was taken into account at each follow-up (1 week, 1 month, 2 months, 3 months, 4 months, and 6 months). Minimum 4 months follow-up was essential to be a part of the study. An interval of $+/-1$ week was considered for each follow-up visit. Data of patients who had prior history of glaucoma were excluded. OHT was defined as IOP $>25 \mathrm{mmHg}$ or an increase of at least $10 \mathrm{mmHg}$ over the follow-up period compared to baseline IOP. Graded OHT was also measured from baseline $(>10 \mathrm{mmHg},>15 \mathrm{mmHg},>20$ $\mathrm{mmHg}$ ). Use of anti-glaucoma medications and the need of surgical intervention to control IOP were analysed in each geographical population. Descriptive statistics included mean and SD for continuous variables. Paired sample $t$-test was used to measure mean differences between pre and postimplant values. To analyse difference between groups, ANOVA with post hoc analysis was used, where $P<0.05$ was considered as statistically significant. Sample size was calculated with ANOVA to have the power of 1 with significance level of 0.05 .

\section{Results}

Effect of 294 implants on IOP was analysed in the study including 100 (34\%), 100 (34\%) and 94 (32\%) implants from White, Latino, and South Asian groups, respectively. Indications in total were $193(65.6 \%), 78(25.3 \%)$ and 23 (7.8\%) for DME, Vein occlusion, and Uveitis respectively. Baseline age, IOP and disease distribution was similar in all the groups. (Table 1) Fifty percent patients were men. The mean age was $66.6 \pm 12.7$ years. $45.5 \%$ of the implanted eyes were pseudophakic at baseline. The mean follow-up period was $25.7 \pm 19.6$ months. Patients received a mean of $1.46 \pm 0.8$ implant.

\section{OHT during follow-up}

The percentage of patients who had IOP $>25 \mathrm{mmHg}$ at any time point during the follow-up period were $0 \%, 8 \%$ and 9.5\% in White, Latino and South Asian groups, respectively. There was no difference between Latino and South Asian group ( $p=0.7, \mathrm{CI}-6.7$ to 10.0 ) IOP rise of at least $10 \mathrm{mmHg}$ from baseline to any time point during follow-up period were 0\%, 12\% and 10\% in White, Latino and South Asian groups, respectively. There was no difference between Latino and South Asian group ( $p=0.6, \mathrm{CI}-7.1$ to 11.0) (Fig. 1).

\section{Sub-analysis of OHT $>20 \mathrm{mmHg}$}

The percentage of patients who had IOP $>20 \mathrm{mmHg}$ at any time point over the follow-up period were 9,28 , and $27 \%$ in 
Table 1 Baseline data of different groups

\begin{tabular}{lllll}
\hline Geography (Ethnicity) & White & South Asian & Latino & $P$ \\
\hline Total implant (No) & 100 & 94 & 100 & $>0.05$ \\
Mean Age & $67 \pm 10$ & $66.2 \pm 14.2$ & $67.6 \pm 13.3$ & $>0.05$ \\
Male (\%) & 52 & 51 & 46 & $>0.05$ \\
DME (\%) & 65 & 60 & 71 & $>0.05$ \\
RVO (CRVO + BRVO) $\%$ & $29(12+17)$ & $27.6(12.8+14.8)$ & $23(10+13)$ & $>0.05$ \\
Uveitis (\%) & 6 & 11.7 & 6 & $>0.05$ \\
Mean baseline IOP & $14.4 \pm 2.7$ & $14.9 \pm 3.2$ & $14.6 \pm 2.4$ & $>0.05$ \\
\hline
\end{tabular}

White, Latino, and South Asian groups respectively. It was significantly higher in Latino ( $p=.0006$, CI 8.3-29.3) and South Asian ( $p=0.0001$, CI 7.2-28.6) compared White population. However, there was no difference between Latino and South Asian group ( $p=0.87, \mathrm{CI}-11.5$ to 13.3) (Fig. 1).

\section{Incidence of very high IOP post implant}

Amongst Whites, none of the patient had IOP $>35 \mathrm{mmHg}$ at any visit post implant. In Latino and South Asian groups IOP $>35 \mathrm{mmHg}$ was reported in $3 \%$ and $2 \%$ respectively. ( $p=0.6$, CI -4.5 to 6.6 ) (Fig. 1$)$.

\section{Management of OHT post implant}

Most of the patients were managed with topical antiglaucoma medications in all the groups except 1 patient in Latino population who required filtering surgery.

\section{Extent of rise in IOP (Mean maximum IOP)}

This was analysed by calculating difference between baseline IOP and maximum IOP recorded during any follow-up visit post implant. The mean maximum IOP rise was $1.1 \pm$ 2.6, 5.4 \pm 5.7 , and $4.3 \pm 5.7 \%$ in White, Latino and South Asian groups, respectively. White population had significantly less mean maximum IOP compared to Latino ( $p$ $<0.0001)$ and South Asian $(p<0.0001)$ group (Fig. 2).

\section{Time of IOP rise}

Mean IOP in South Asian and Latino group was significantly higher from the baseline up to 3 months. However White population did not show any significant change at any of the visit up to 4 months.

\section{OHT in >1 implant patients}

There was no difference in proportion of the eyes with IOP $>20 \mathrm{mmHg}$ between groups with more than 1 implant and single implant within each geographic group. Furthermore Latino and South Asian group were similar in $>1$ implant
( $p=0.6, \mathrm{CI}-23.5$ to 26.5$)$ and single $(p=0.9, \mathrm{CI}-14.4$ to 15.5). White had significantly less proportion compared to Latino ( $>1$ implant $p=0.01$, CI 5-36.7, single implant $p=.01$, CI 2.3-29.7) and South Asian group (single implant $p=0.01$, CI 2.7-31.1). However, it was not different from South Asian group in $>1$ implant $(p=0.1$, CI -3.4 to 43.2 ).

\section{Difference between pseudophakic and phakic}

There was no difference in pseudophakic and phakic eyes with IOP rise $>20 \mathrm{mmHg}$ within each geographic group. Furthermore, Latino and South Asian group were similar in pseudophakic ( $p=.5, \mathrm{CI}-16.9$ to 26.9$)$ and phakic eyes ( $p$ $=.6, \mathrm{CI}-12.1$ to 18.7$)$. White had significantly less proportion compared to Latino (Pseudophakic $p=0.03$, CI 1.6-35.8, Phakic $p=0.01$, CI 2.3-29.7) and South Asian group (Phakic $p=.002$, CI 7.0 to 31.3 ). However, it was not different in pseudophakic patients of South Asian group (Pseudophakic $p=0.22$, CI 7.6-35.9).

\section{Difference between vitrectomized vs. non- vitrectomized eyes}

There was no difference in eyes with IOP rise $>20 \mathrm{mmHg}$ in vitrectomized vs non-vitrectomized eyes within each geographic group. Furthermore, Latino and South Asian group were similar in vitrectomized ( $p=0.5, \mathrm{CI}-27.9$ to 43.1 ) and non-vitrectomized ( $p=0.8, \mathrm{CI}-12.0$ to 14.0 ) eyes. White had significantly less proportion compared to other groups in non-vitrectomized eyes. (Latino; $p=0.002, \mathrm{CI}$ 6.1-28.0, South Asian group; $p=0.001$, CI 7.2-28.9). However, it was not different in vitrectomized eyes. (Latino; vitrectomized $p=0.5, \mathrm{CI}-32.9$ to 46.7 , South Asian group; $p=0.9, \mathrm{CI}-45.8$ to 44.5$)$.

\section{Discussion}

GEODEX-IOP study analyses the real-world data of IOP fluctuations during follow-up in different geographic populations. There have been very few studies with real life data after Ozurdex implant such as CHROME and SAFODEX [13, 14]. Most of them were focused on single geographic population. There have been large variations in study results in terms of $>25 \mathrm{mmHg}$ IOP post implant, such as $12 \%$ in study by Reid et al. [18] and $50 \%$ in study by Meyer et al. [19]. GEODEX-IOP study showed lower incidence of IOP rise $>25 \mathrm{mmHg}$ compared to CHROME and SAFODEX study. To analyse this difference, a subanalysis was performed keeping the IOP $>20 \mathrm{mmHg}$, which showed data more similar to the SAFODEX, CHROME and other studies. The present study indicates that most of the 
Fig. 1 Proportion of patients with high IOP in different groups

Fig. 2 Mean maximum IOP during different groups
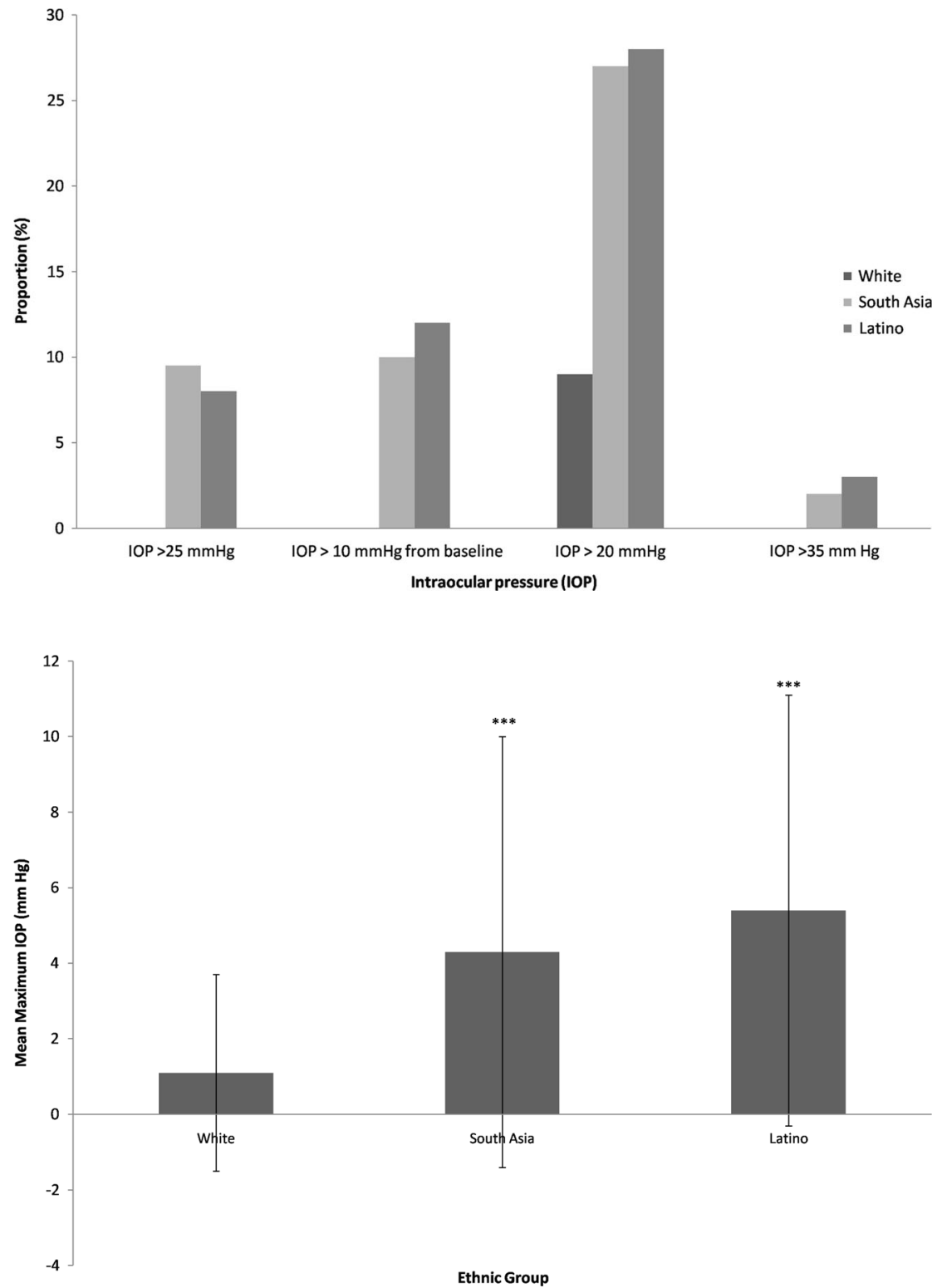

patients fluctuate between $20-25 \mathrm{mmHg}$ after Ozurdex implant. South Asian and Latino population had statistically significant more cases of OHT compared to Whites. South Asian and Latino population behaved similarly on all the parameters tested in the study. White population had lower risk of IOP rise compared to both the other groups on most of the parameters tested. This is an important difference revealed by GEODEX-IOP study because Asian and Latino population data was not predominant in previous similar studies. Incidence of very high IOP $>35 \mathrm{mmHg}$ was low in the present study (2.2-3.5\%) compared to the data revealed by MEAD, HURON, GENEVA and CHROME (5.9-8.8\%) $[8,9,11,14]$.

Management in this study was similar to other studies as most of the cases were controlled on topical IOP lowering medications. To know the severity of IOP rise, highest IOP from baseline was analysed and showed that it was greater in South Asian and Latino population compared to White. Furthermore, very high IOP was not seen in White population and had low incidence in rest of the population groups. Multiple injections also did not affect the rise of IOP within each population as shown in other studies [13]. However, it did differ between groups. The present study shows significant rise of IOP compared to baseline in South Asian and Latino groups. However White population did not show any change from baseline.

Dexamethasone differs from triamcinolone in its pharmacologic activity, lipid solubility and delivery requirements. Dexamethasone is less lipophilic and does not accumulate to the same extent in the trabecular meshwork, and therefore may have lower risk of IOP increases compared to other intravitreal steroids [23-25]. 
This study has limitations in terms of a retrospective design. Treatment of OHT was at the discretion of clinicians rather than as per standardised protocol. However, GEODEX is the first study to reveal the group difference in IOP rise after dexamethasone Implant. Study results are in agreement with the meta-analysis on global variation in glaucoma by Venediktos et al. [26]. However, studies including more population groups (African, East Asian) to better understand the differences regarding ethnic variation in IOP after implant are required.

\section{Summary}

\section{What was known before}

- Intravitreal dexamethasone implant causes rise in IOP in studied population.

\section{What this study adds}

- Possibility of variable IOP rise in different geographic groups.

\section{Compliance with ethical standards}

Conflict of interest Ashish Sharma-consultant: Novartis India, Allergan Global, Intas India, Bayer India. BD Kuppermann-clinical research: Alcon, Alimera, Allegro, Allergan, Apellis, Clearside, Genentech, GSK, Ionis, jCyte, Novartis, Regeneron, ThromboGenics; consultant: Alimera, Allegro, Allergan, Cell Care, Dose, Eyedaptic, Galimedix, Genentech, Glaukos, Interface.

Biologics, jCyte, Novartis, Ophthotech, Regeneron, Revana, Theravance Biopharma. Francesco Bandello-consultant: Allergan, Bayer, Boehringer- Ingelheim, Fidia Sooft, Hofmann La Roche, Novartis, NTC Pharma, Sifi, Thrombogenics, Zeiss. Anat Loewensteinconsultant: Allergan, Novartis, Roche, Notal Vision, Fiorsightslabs, Beyeonics, Bayer Health Care.

Publisher's note Springer Nature remains neutral with regard to jurisdictional claims in published maps and institutional affiliations.

\section{References}

1. Zhang X, Clark AF, Yorio T. FK 506-binding protein 51 regulates nuclear transport of the glucocorticoid receptor beta and glucocorticoid responsiveness. Investig Ophthalmol Vis Sci. 2008;49:1037-47.

2. Johnson DH, Bradley JM, Acott TS. The effect of dexamethasone on glycosaminoglycans of human trabecular meshwork in perfusion organ culture. Investig Ophthalmol Vis Sci. 1990;31:2568-71.

3. Steely HT, Bowder SL, Julian MB, Miggans ST, et al. The effects of dexamethasone on fibronectin expression in cultured human trabecular meshwork cells. Investig Ophthalmol Vis Sci. 1992;33:2242-50.

4. Rohen JW, Linner E, Witmer R. Electron microscopic studies on the trabecular meshwork in two cases of corticosteroid-glaucoma. Exp Eye Res. 1973;17:19-31.

5. Roll P, Benedikt O. Electron microscopic studies of the trabecular meshwork in corticosteroid glaucoma (in German). Klin Monatsbl Augenheilkd. 1979;174:421-8.

6. Singh IP, Ahmad SI, Yeh D, Challa P, et al. Early rapid rise in intraocular pressure after intravitreal triamcinolone acetonide injection. Am J Ophthalmol. 2004;138:286-7.

7. Sharma A, Patil AJ, Gupta N, Estrago-Franco MF, et al. Effects of triamcinolone acetonide on human trabecular meshwork cells in vitro. Indian J Ophthalmol. 2014;62:429-36.

8. Haller JA, Bandello F, Belfort R,Jr, Blumenkranz MS, Ozurdex GENEVA Study Group, Li J. et al. Dexamethasone intravitreal implant in patients with macular edema related to branch or central retinal vein occlusion twelve-month study results. Ophthalmology.2011;118:2453-60.

9. Boyer DS, Yoon YH, Belfort R Jr, Bandello F, et al. Ozurdex MEAD Study Group. Three-year, randomized, sham-controlled trial of dexamethasone intravitreal implant in patients with diabetic macular edema. Ophthalmology. 2014;121:1904-14.

10. Bellocq D, Korobelnik JF, Burillon C, Voirin N, et al. Effectiveness and safety of dexamethasone implants for post-surgical macular oedema including Irvine-Gass syndrome: the EPISODIC study. Br J Ophthalmol. 2015;99:979-83.

11. Lowder C, Belfort R Jr, Lightman S, Foster CS, et al. Ozurdex HURON Study Group. dexamethasone intravitreal implant for noninfectious intermediate or posterior uveitis. Arch Ophthalmol. 2011;129:545-53.

12. Dot C, El Chehab H, Russo A, Agard E. Ocular hypertension after intravitreal steroid injections: clinical update as of 2015. J Fr Ophtalmol. 2015;38:656-64.

13. Malclès A, Dot C, Voirin N, Vié AL, et al. Safety of intravitreal dexamethasone implant (ozurdex): the SAFODEX study. Incidence and risk factors of ocular hypertension. Retina. 2017;37:1352-9.

14. Lam WC, Albiani DA, Yoganathan P, Chen JC, et al. Real-world assessment of intravitreal dexamethasone implant $(0.7 \mathrm{mg})$ in patients with macular edema: the CHROME study. Clin Ophthalmol. 2015;9:1255-68.

15. Sarda V, Fajnkuchen F, Nghiem-Buffet S, et al. Early efficacy of dexamethasone implant $\left(\right.$ OZURDEX $\left.^{\circledR}\right)$ in diabetic macular edema: Real life study. J Fr Ophtalmol. 2017;40:408-13.

16. Pommier S, Meyer F, Guigou S, Barthelemy T, et al. Long-term real-life efficacy and safety of repeated Ozurdex ${ }^{\circledR}$ injections and factors associated with macular edema resolution after retinal vein occlusion: the REMIDO 2 study. Ophthalmologica 2016;236: 186-92.

17. Jiménez-Gómez B, González-Montpetit M, Fonollosa Calduch A, Orive Bañuelos A, et al. Effects of ozurdex on intraocular pressure. A real life clinical practice study. Arch Soc Esp Oftalmol. 2015;90:421-5.

18. Reid GA, Sahota DS, Sarhan M. Observed complications from dexamethasone intravitreal implant for the treatment of macular edema in retinal vein occlusion over 3 treatment rounds. Retina 2015;35:1647-55.

19. Meyer LM, Schönfeld CL. Secondary glaucoma after intravitreal dexamethasone $0.7 \mathrm{mg}$ implant in patients with retinal vein occlusion: a one-year follow-up. J Ocul Pharmacol Ther. 2013;29:560-5.

20. Theodoropoulou S, Ellabban AA, Johnston RL, Cilliers H, et al. Short-term safety of dexamethasone implant for treatment of macular edema due to retinal vein occlusion, in eyes with 
glaucoma or treated ocular hypertension. Graefes Arch Clin Exp Ophthalmol. 2017;255:725-32.

21. Mazzarella S, Mateo C, Freixes S, Burés-Jelstrup A, et al. Effect of intravitreal injection of dexamethasone $0.7 \mathrm{mg}$ (Ozurdex ${ }^{\circ}$ ) on intraocular pressure in patients with macular edema. Ophthalmic Res. 2015;;54:143-9.

22. Rudnicka AR, Mt-Isa S, Owen CG, Cook DG, et al. Variations in primary open-angle glaucoma prevalence by age, gender, and race: a Bayesian meta-analysis. Investig Ophthalmol Vis Sci. 2006; 47:4254-61.

23. Thakur A, Kadam R, Kompella UB. Trabecular meshwork and lens partitioning of corticosteroids: implications for elevated intraocular pressure and cataracts. Arch Ophthalmol. 2011;129:914-20.
24. Jaffe GJ, Martin D, Callanan D, Pearson PA, et al. Fluocinolone Acetonide Uveitis Study Group. Fluocinolone acetonide implant (Retisert) for noninfectious posterior uveitis: thirty-four-week results of a multicenter randomized clinical study. Ophthalmology. 2006;113:1020-7.

25. Chin EK, Almeida DRP, Velez G, Peraire M, et al. Ocular hypertension after intravitreal dexamethasone (Ozurdex) sustained-release implant. Retina.2017;37:1345-51.

26. Venediktos VKapetanakis, Michelle PYChan, Foster PJ, Cook DG, et al. Global variations and time trends in the prevalence of primary open angle glaucoma (POAG): a systematic review and meta-analysis. $\mathrm{Br} \mathrm{J}$ Ophthalmol. 2016; 100:86-93. 